\title{
RELATIONSHIP BETWEEN INTERNATIONAL PORTFOLIO INVESTMENTS AND THE COUNTRY GOVERNANCE QUALITY
}

DOI: $10.17261 /$ Pressacademia.2020.1272

PAP- V.11-2020(45)-p.226-227

Eyyup Kaya ${ }^{1}$, Mine Aksoy ${ }^{2}$

${ }^{1}$ Yalova Üniversitesi, Sosyal Bilimler Enstitüsü, İşletme Bölümü, Yalova, Turkey. eyvubkaya63@gmail.com, ORCID: 0000-0000-0000-000

2 Yalova University, Faculty of Economics and Administrative Sciences, Yalova, Turkey. maksoy@yalova.edu.tr, ORCID: 0000-0002-4773-1770

\section{To cite this document}

Kaya, E., M. Aksoy. (2020). Relationship between international portfolio investments and the country governance quality. PressAcademia Procedia (PAP), V.11, p.226-227.

Permemant link to this document: http://doi.org/10.17261/Pressacademia.2020.1272

Copyright: Published by PressAcademia and limited licensed re-use rights only.

\begin{abstract}
Purpose- The purpose of this study is to analyze the relationship between international portfolio investments and the country governance quality.

Methodology- In this study, based on panel data analysis of 18 emerging market countries from 2002 to 2018 , the impact of governance quality on international portfolio investments was examined. These emerging countries are Argentina, Brazil, Chile, Colombia, Greece, Hungary, Egypt, Indonesia, India, Malaysia, Mexico, Peru, Poland, Philippines, Russia, South Africa, Thailand and Turkey. The main proxies for a country's governance quality are the World Governance Indicators (WGI).

Findings- As a result of the analysis, it was observed that the quality of governance indicators, excluding political stability and absence of violence, had a positive effect on international portfolio investments. Voice and accountability were observed to be the variable that most affected portfolio investments. Voice and accountability were followed by government effectiveness. Control of corruption, rule of law and regulatory quality were other indicators of governance that affected portfolio investments respectively. In this study, foreign direct investments, current account deficit, stock market size and stock market returns were used as control variables. As a result of the analysis, it was concluded that there is a negative relationship between foreign direct investments, current account deficit and international portfolio investments. There is also a positive relationship between stock market size, stock market returns and international portfolio investments. Conclusion- The empirical results tend to confirm the positive influence of governance quality on international portfolio investments.
\end{abstract}

Keywords: Governance quality, international portfolio investments, emerging markets

JEL Codes: F32, F36, G15

\section{ULUSLARARASI PORTFÖYYATIRIMLARI VE ÜLKE YÖNETiŞiM KALITESI ARASINDAKi İLiŞKi}

\section{ÖZET}

Amaç- Bu çalışmanın amacı, uluslararası portföy yatırımları ile ülke yönetişim kalitesi arasındaki ilişkiyi analiz etmektir.

Yöntem-Bu çalışmada, panel veri analizine kullanılarak, 2002-2018 dönemi ve gelişmekte olan 18 için, yönetişim kalitesinin uluslararası portföy yatırımları üzerindeki etkisi incelenmiştir. Analize dahil edilen ülkeler, Türkiye, Arjantin, Brezilya, Endonezya, Filipinler, Güney Afrika, Hindistan, Kolombiya, Macaristan, Malezya, Meksika, Mısır, Peru, Polonya, Rusya, Şili, Tayland ve Yunanistan'dır.

Bulgular- Analizler sonucunda, politik istikrar hariç yönetişim göstergeleri kalitesinin iyi olmasının uluslararası portföy yatırımlarını olumlu yönde etkilediği görülmüştür. İfade özgürlüğü ve hesap verebilirliğin portföy yatırımlarını en çok etkileyen değişken olduğu gözlemlenmiştir. ifade özgürlüğü ve hesap verebilirliği hükümet etkinliği takip etmiştir. Yolsuzluğun kontrolü, hukukun üstünlüğü ve düzenleyicilerin kalitesi sırasıyla portföy yatırımlarına etki eden diğer yönetişim göstergeleridir. Çalışmada kontrol değişkenle ri olarak kullanılan doğrudan yabancı yatırımlar ve cari denge ile uluslararası portföy yatırımları arasında negatif; hisse senedi piyasa büyüklüğü ve borsa getirisi ile uluslararası portföy yatırımları arasında pozitif bir ilişki olduğu sonucuna ulaşılmıştır.

Sonuç-Ampirik sonuçlar yönetişim kalitesinin uluslararası portföy yatırımları üzerindeki olumlu etkisini desteklemektedir.

Anahtar Kelimeler: Yönetişim kalitesi, uluslararası portföy yatırımları, gelișmekte olan ülkeler.

JEL Kodları: F32, F36, G15. 


\section{KAYNAKÇA}

Abdioglu, N., Khurshed, A. \& Stathopoulos, K. (2013). Foreign institutional investment: Is governance quality at home importa nt? Journal of International Money and Finance, 32, 916-940.

Aggarwal, R., Klapper, L. \& Wysocki, P. D. (2005). Portfolio Preferences of Foreign Institutional Investors. Journal of Banking and Finance, 29, 2919-2946.

Aggarwal, R., Erel, I., Stulz, R. \& Williamson, R. (2009). Differences in governance practices between U.S. and foreign firms: measurement, causes, and consequences. Review of Financial Studies, 22, 3131-3169.

Aggarwal, R., Klapper, L., Erel, I., Ferreira, M. \& Matos, P. (2011). Does Governance Travel around the World? Evidence from Institutional Investors. Journal of Financial Economics, 100(1), 154-181.

Alfaro, L., S. Kalemli-Ozcan \& V. Volosovych (2008). Why Doesn't Capital Flow from Rich to Poor Countries? an Empirical Investigation. The Review of Economics and Statistics, 90(2), 347-368. http://dx.doi.org/10.1162/rest.90.2.347.

Cengiz, V., \& Karacan, R. (2015). Gelişmekte Olan Ülkelere Yönelik Sermaye Hareketleri ve Ekonomik Sonuçlari. International Journal of Economic \& Administrative Studies, 8(15), 327-344.

Chipalkatti, N., Q. V. Le, \& M. Rishi. (2007). Portfolio Flows to Emerging Capital Markets: Do Corporate Transparency and Public Governance Matter? Business and Society Review, 112 (2), 227-249. http://dx.doi.org/doi:10.1111/basr.2007.112.issue-2.

Clark, J. \& E. Berko. (1996). Foreign Investment Fluctuations and Emerging Market Stock Returns: The Case of Mexico. Federal Reserve Bank of New York, Research Paper No:9635.

De Santis, R. \& M. Lührmann. (2006) ECB Working Paper on the Determinants of External Balances and Net International Portfolio Flows, No.651.

Kaufmann, D., Kraay, A. \& M. Mastruzzi. (2010). Response to What Do the Worldwide Governance Indicators Measure \& Quest. European Journal of Development Research, 22(1), 55-58.

Le \& Zak. (2006). Corruption and capital flight: an empirical assessment. International Economic Journal, 20(1), 532-540. https://doi.org/10.1080/10168730601027161.

Leuz, C., Lins, K. V. \& Warnock, F. E. (2009). Do Foreigners Invest Less in Poorly Governed Firms? Review of Financial Studies, 22 (8), 3245 3285.

Le, Quan \& Rishi, Meenakshi. (2006). Corruption and Capital Flight: An Empirical Assessment. International Economic Journal, $20,523-540$. https://doi.org/10.1080/10168730601027161.

World Bank (2018). The Worldwide Governance Indicators. Erişim adresi: https://info.worldbank.org/governance/wgi/ . 